Editorial

\title{
Sustainability of Local and Global Food Chains: Introduction to the Special Issue
}

\author{
Gianluca Brunori and Francesca Galli * \\ Department of Agriculture, Food and Environment, University of Pisa, via del Borghetto, 80, 56124 Pisa, Italy; \\ gianluca.brunoril@unipi.it \\ * Correspondence: francesca.galli@for.unipi.it; Tel.: +39-050-221-8979
}

Academic Editor: Marc A. Rosen

Received: 25 July 2016; Accepted: 26 July 2016; Published: 8 August 2016

\begin{abstract}
Sustainability assessment is one of the keys to competition by food supply chains over sustainability. The way it is conceived and embodied into decision-makers' choices affects the competitiveness of local and global chains. Science-based assessment methodologies have made substantial progress, but uncertainties—as well as interests at stake-are high. There are no science-based methods that are able to give an unchallenged verdict over the sustainability performance of a firm, let alone a supply chain. Assessment methods are more suited for medium-large firm dimensions, as planning, monitoring, and reporting are costly. Moreover, the availability of data affects the choice of parameters to be measured, and many claims of local food are not easily measurable. To give local chains a chance to operate on a level playing field, there is the need to re-think sustainability assessment processes and tailor them to the characteristics of the analysed supply chains. We indicate seven key points on which we think scholars should focus their attention when dealing with food supply chain sustainability assessment.
\end{abstract}

Keywords: sustainability assessment; local; global; food chains

\section{Sustainability as a New Terrain of Competition}

According to neoclassical economic theory, market transactions are impersonal: all a buyer needs is knowledge of the price for a given commodity. In this ideal world, when the consumer makes a choice, she may only consider her expected utility. Many market policies tend to orientate to this ideal state; for example, by reducing tariff barriers, simplifying labelling rules, harmonizing common technical standards or sanitary rules, or reducing controls at borders. To guarantee the functioning of markets, public authorities set procedures, establish information and control systems, distribute roles and responsibilities among actors, and identify authorities to ensure that commodities are safe and compliant with a minimum set of quality rules. All these efforts should, in theory, make the food system a "black box" for consumers-an object whose internal mechanisms do not need to be known as long as it works effectively. Recurrent food scandals show that these efforts are not sufficient: free circulation of commodities on a global scale makes the system vulnerable to unforeseen and unintended disease outbreaks and fraudulent behaviour.

Concerns and anxieties are amplified by a lack of information and transparency. As lack of information turns into lack of trust [1], consumers increasingly aim at "looking into the black box", and increasingly shape their food choices according to new claims and aspirations of how sustainable food systems should perform.

In reaction to these concerns, information becomes a key component of the product and an object of competition: big players have invested in technologies, measurement tools, certification schemes, and social reporting to develop value-based coalitions with consumers and improve their sustainability performance. 
The availability of information on a product changes the product itself, differentiating it from similar products for which there is less available information. Information changes consumers' behaviour, as it brings attention to issues hitherto considered unproblematic. When information is available, actors of the food system are increasingly encouraged to reflect on the consequences of their actions: consumers are facilitated in their search for coherence with their responsibilities as citizens, private firms are asked to account for the consequences of their activities well beyond operations they control directly, public institutions are encouraged to harmonize the principle of free circulation of commodities to nature conservation, human rights, public health, and ethical principles. Media, scientific research, institutional bodies, and even commercial communication address these issues in an increasingly systematic way. Concepts such as "ecological footprint", "virtual water", "food miles", "product life cycle", "indirect land use", and "social metabolism" - to mention just a few-are recognized well beyond a small circle of specialists. Although some are based on limited data and far-from-robust methodologies, these concepts affect consumers' choices and lifestyles.

The new form of competition is not only between firms, it is also between supply chains [2]. Big players in the food system build their brand reputation by controlling information and setting standards over the whole product life cycle. The standards they develop add —and sometimes replace-private governance to public governance. To build trust, they also engage in patterns of "extended governance" that imply intense interaction with stakeholders and disclosure of information [3]. In contrast, coordination of local chains-often constituted by farmers and artisanal producers-is mainly achieved through informal relations. Farmers producing cottage products directly control the whole product cycle, and respond personally for the quality of their products. At farmers' markets, producers exchange information, values, and images through face-to-face encounters [4]. When producers and consumers belong to the same communities-as as in the case of Community Supported Agriculture (CSA), Association pour le Maintien d'une Agriculture Paysanne (AMAPS), or Solidarity Purchase Groups (SPG) - "social control" through frequent interaction is possible [5,6]. This level of informality can be an important competitive advantage of local food, as personal credibility allows communication of sustainability features that cannot be measured but are nevertheless perceived as real.

\section{Local Food and Sustainability Assessment: The End of a Competitive Advantage?}

In the absence of reliable information and a lack of trust in globalized chains, local food purchasing has become a strategy for some consumers to keep control of the consequences of their choices. In many consumers' imaginations, "local" is associated with attributes such as "organic", "artisanal", "biodiversity", "natural", "fresh", "seasonal", and "nutritious" [7-9]. To comply with the demand for local food, producers have reduced the physical distance between production and consumption, established direct links with consumers, redefined the area of sourcing, set quality criteria for raw materials, added value to local resources, and developed appropriate communication strategies. "Local" has imposed itself as an alternative model to global food provisioning: small, diverse, and sustainable against big, standardized, and destructive to natural resources [10]. The growth of "the local", together with increasing concern for sustainability and suspicion of industrial food, has stimulated big players to take the issue of sustainability seriously. Large retailers and multinational enterprises provide an increasing amount of information and broaden the range of claims made about their products. Environmental, health, and ethical issues are a growing component of food business communication strategies, which help them to gain a competitive advantage and pre-empt formal regulations [11]. Not surprisingly, "localization" has also taken place in conventional business. It is not uncommon to find supermarkets where the availability of local products is organized and promoted. Some of them have revised the concept of retailing, building upon the supply of a myriad of products with strong link to their "terroir".

As a consequence, local and global chains tend to converge. Appropriation by the whole industry of features originally introduced by local actors may be a threat to the niches local players have built up over time. As both local and global chains address sustainability, and consumers can find "sustainable" 
products at a lower price, the perception that local chains are more sustainable than global chains may be challenged. Moreover, not all local chains have the same performance. Accidents or frauds-always possible when supply chains are opaque-may undermine the reputation of local food producers as well. If consumers are encouraged to choose between products coming from different chains, they may not find enough evidence to support the choice of local instead of global products. This raises the need to provide consumers with adequate information and decision-making tools.

\section{Sustainability Assessment of Local and Global Chains: Methodological Issues}

Sustainability assessment will be one of the keys of competition over sustainability. The way it will be conceived and embodied into decision-makers' choices will affect the competitiveness of local and global chains. Science-based assessment methodologies have made substantial progress, but uncertainties, as well as interests at stake, are high. There are no science-based methods that are able to give an unchallenged verdict over the sustainability performance of a firm, let alone a supply chain. Assessment methods are more suited to medium-large firm dimensions, as planning, monitoring, and reporting are costly. Moreover, the availability of data affects the choice of parameters to be measured, and many claims of local food are not easily measurable. To give local chains a chance to operate on a level playing field, there is the need to re-think sustainability assessment processes and tailor them to the characteristics of the analysed supply chains.

The European research project GLAMUR (GLAMUR research project (FP7-311778, www.glamur.eu) has been investigating which aspects in terms of sustainability and value distinguish a global from a local food supply chain. It has developed a multidimensional approach to the analysis of the performance of different supply chain configurations-balancing economic determinants with other attributes related to health, environment, society, and ethics. Dynamics in the value chains, socio-economic and biophysical indicators, local/global categories, and their limits have been explored. A detailed overview is provided in the paper by Brunori et al. [12] included in this special issue- - here we indicate seven key points on which we think scholars should focus their attention when dealing with food supply chains sustainability assessment.

\subsection{The Multidimensionality of Sustainability}

Discourse over sustainability often focus on the environmental dimension. The social dimension is more rarely taken under consideration in assessment, and exercises for assessing health and ethics are only in their infancy. Each of these dimensions raises a number of methodological issues, as most of the impacts are indirect (occurring after a pathway of consequences) and delayed (occurring only after a time lag). This implies that a wide range of potential impacts should be examined simultaneously. Moreover, dimensions belonging to the social sphere are far less easy to capture in a quantitative way. Grivins and colleagues [13] make an effort in this sense, by comparatively analysing the social performance of global and local berry supply chains (in Latvia and Serbia) and exploring the ways in which the social dimension is embedded in the overall performance of food supply chains.

Several papers included in this special issue address food chains' sustainability performance, explicitly considering its multidimensional nature in different food sectors: for example, Schwarz and colleagues [14] analyse economic development, resource use, labour relations, distribution of added value, and governance for local Belgian and global Peruvian asparagus value chains. Galli and colleagues [15] compare local and global bread chains across 19 attributes of sustainability performance spanning economic, social, environment, health, and ethics. Schmitt et al. [16] compare cheese value chains in Switzerland and the UK in terms of affordability, creation and distribution of added value, information and communication, consumer behaviour, resource use, biodiversity, nutrition, and animal welfare. 


\subsection{Boundary Setting and Definitions}

Supply chains are mental constructs applied to formal or informal organizations and can be defined as the "entire networks of entities, directly or indirectly interlinked and interdependent in serving the same consumer or customer" (http:/ / www.businessdictionary.com/definition/supply-chain.html). Assessing food chains means "following the product"; that is, analysing the material stream from the raw material to the final product. However, doing this may lead to overlooking the importance of joint processes and products linking different chains. Several questions that explore this complex dynamic arise, such as: how to assess local produce that is sold in a local supermarket outlet? How to evaluate a "local" sandwich served in a global fast food chain? How to assess a local wine (local grapes and local wine for local consumers) when its producer also makes wine with grapes sourced globally and sells them in Asia?

As part of a multidimensional sustainability assessment of local and global wine chains, Touzard and colleagues [17] make an attempt to objectivize which aspects of wine are local and which are global by referring to the geographical distance between consumption and production, the number of intermediaries along the value chain, the nature of incorporated resources, product identity, and the leading actors as regards governance.

There are boundary definition problems also related to the variability of relational and spatial configurations of supply chains in time. Given that many markets work as "spot" markets, supply chain configurations are subject to continuous change, depending on market conditions. In this case, boundary setting could be a difficult task. When, on the contrary, food supply chains are coordinated through governance tools (e.g., Protected Designations of Origin schemes), assessment can be a relatively easier task, as governance gives configurations a relative stability.

\subsection{Chains vs. Systems}

Assessment of supply chains may not be sufficient to properly assess sustainability. A product can be safe and nutritious, but if not included in a proper diet, its consumption may generate health problems. Fish is nutritious and healthy, but a generalization of fish-based diets may bring too much pressure on fishery stocks. Sustainable fishing techniques may not be sufficient when such pressure on stocks occurs. To address the level of sustainability with regard to issues such as these, a system-based approach would be needed. With a systemic approach, the impact of a product may be anticipated through design (for example, to avoid waste, the product could have a longer shelf-life or a size tailored to customers' needs). Firms may coordinate among themselves to reuse or recycle leftovers. Firms' communication may provide information about sustainable consumption, as in the case of the nutritional labels or on indications about how to recycle. In their review, De Laurentiis and colleagues [18] turn to a systemic approach and identify synergies and trade-offs between water and energy systems and food systems, and therefore opportunities for efficient resource use and reduced environmental impact both in food production practices and consumption choices. Employing sustainable production methods in agriculture, changing diets, and reducing waste in all stages of the food chain are three main identified pathways to achieving food security in a (more) sustainable way.

\subsection{What Are the Implications of Different Global-Local Value Chain Configurations on Sustainability?}

To be able to assess the sustainability of local food chains, and to compare them with other spatial configurations, it is necessary to understand the implications of their specificity. In other words, we need to understand whether the characteristics that allow us to classify the chain as "local" or "global" are decisive in obtaining a given sustainability performance. This question refers to the limits and potential for each actor in the food chain to improve their own sustainability performance and the overall supply chain to which they belong.

Oostindie and colleagues [19] show how - for the case of local and global pork chains Italy and the Netherlands-performance assessment turns out to be intrinsically interwoven with place-specific 
and multi-facetted local-global interaction patterns and mutual interdependencies. Food chain performance analysis is much more about in-depth analysis of place-specific dynamics, interaction, and strategies, rather than the description of static and de-contextualized performance profiles.

\subsection{How to Turn Sustainability Criteria into Metrics?}

Sustainability assessment is expected to measure the distance of existing situations from desired situations and to compare different situations in a consistent way. A number of researchers have engaged in the endeavour of providing sustainability metrics (see [20] for a review). Despite these efforts and the growth of an "indicator industry", we are still far from having reached satisfactory results in measuring sustainability [21]. Several authors have proposed reasons why outcomes are so disappointing; for example, uncertainty over the meaning of sustainability, different priorities given by different groups, insufficient knowledge of the realities under observation. Aware of these limitations, there is the need to explore multiple measurement methods and indicators, with the purpose of identifying the limits to existing methodologies and possible future research avenues.

\subsection{How to Capture the Evolution of Food Chain Performance?}

Different supply chain configurations may have different performance evolutions. Assessing performance in a static way-that is, measuring indicators in a given time-would not adequately capture the motivations, endeavours, and the capacity of the actors involved to change. Re-localization initiatives may be a response to globalizing chains, whereas, conversely, global chain actors may re-integrate and re-incorporate "local elements" in their business strategy as specific responses to a renewed attention to their potential societal benefits. Similarly, local chains may incorporate global elements to improve their resource use efficiency.

When assessing local food chains, one can detect very radical declared goals and very innovative practices, but also inefficiencies related to a lack of resources or to inexperience. Global food chains, on the contrary, can be very efficient in pursuing given sustainability indicators, but may be rigid in adapting their sustainability efforts to changing conditions and societal needs. Moreover, the necessity of optimizing their processes based on the chosen set of indicators of performance generates, as a side effect, a systemic neglecting of those dimensions of sustainability that are more difficult to define and quantify in an uncontested way-i.e., those referring to cultural values and ethical considerations.

\subsection{How to Account for Different Interests, Values, and Perceptions of Sustainability?}

Multidimensionality raises a key methodological issue: metrics for the assessment cannot be summed up to each other because some of them are based on observations referring to different dimensions and scales. This implies that the quantification of some of the assessments is obtained by conflating non-equivalent descriptive domains, reducing non-reducible representations and models, and requiring the use of different measurement units. Moreover, wide-ranging literature on food systems provides multiple perspectives and world views. Various stakeholders define food and food systems in non-equivalent ways. Furthermore, the relative importance of dimensions may change according to different points of view in relation to values, interests, and knowledge: who decides whether the analysis is addressing the "right" set of attributes of performance [22]? How to handle the fact that different social actors carry legitimate but contrasting perceptions of what should be considered as an "improvement"?

Multi-criteria analysis overcomes the simplification that is generated through cost-benefit analysis-which only determines a reduction to costs and benefits in monetary terms subject to available information. However, it does not address the incommensurability of values. A reflection on new ways of developing participatory integrated assessments is needed.

Gamboa and colleagues [23] set out to demonstrate that the pre-analytical adoption of different narratives about the food system leads to non-equivalent assessments of the performance of food supply chains. In order to do so, the authors identify a set of relevant narratives on food supply chains 
in Spanish and Catalan contexts and the pertinent attributes needed to describe and represent food supply chains within the different perspectives or narratives. Hence, they carry out an integrated assessment of three organic tomato supply chains from different perspectives, enabling the analyst to characterize the performance of food supply chains from different perspectives and to identify the expected trade-offs of integrated assessment.

Galli and colleagues [15] also address the diversity of visions around what counts as sustainable food. By integrating qualitative and quantitative data, stakeholder consultation, and multi-criteria analysis, the authors align the visions and the multiple meanings of sustainability. Results emphasize the value of combining science-led evidence with socio-cultural values, multidimensional sustainability assessment as a self diagnosis tool, and the need to identify shared assessment criteria by communities of reference.

\section{Sustainability Assessment of Local and Global Chains: Implications in Policies and Practice}

Given that sustainability is a new competition terrain, sustainability assessment will be a key aspect of food system governance. Smith and colleagues [24] consider how policy can address food chains within a wider commitment to food sustainability, identifying processes of engagement-by public policy, the market, and civil society—and points of engagement offered by existing policy initiatives at global, EU, national, and sub-national policy levels. Scenarios as possible "food futures" are used to illustrate the impacts on the "bigger policy picture" along the local-global continuum. Connections are made between policy frameworks (as processes and points of engagement for food policy) and the food "futures".

Sustainability assessment is not only about measurement methods, it is first of all a field over which different interests, representations, and discourses confront each other. Sustainability is a "consensus frame" [15], something on which everybody is willing to engage and which, given its relatively broad and undefined meaning, is open to different interpretations and very diverse applications. A "consensus frame" allows very different worlds-in this case local and global food chains - to talk to each other and to learn from each other through deliberation.

To be able to generate change, sustainability assessment should be an open, diffuse, inclusive process-implying a continuous interchange between science, civil society, business, and public administrations, and bringing a shared and more robust knowledge.

Acknowledgments: The research has received funding from the European Union's Seventh Framework Programme for research, technological development and demonstration under grant agreement number 311778, Global and Local food chain Assessment: a Multidimensional performance-based approach (GLAMUR) project. Further information is available on the website http://www.glamur.eu/. The views expressed in this paper are solely those of the authors.

Author Contributions: Both authors equally contributed to writing and revising this manuscript.

Conflicts of Interest: The authors declare no conflict of interest. The founding sponsors had no role in the design of the study; in the collection, analyses, or interpretation of data; in the writing of the manuscript, and in the decision to publish the results.

\section{References}

1. Karstens, B.; Belz, F.-M. Information asymmetries, labels and trust in the german food market: A critical analysis based on the economics of information. Int. J. Advert. 2006, 25, 189-211.

2. Seuring, S.; Gold, S. Sustainability management beyond corporate boundaries: From stakeholders to performance. J. Clean. Prod. 2013, 56, 1-6. [CrossRef]

3. Sacconi, L. A social contract account for csr as an extended model of corporate governance (i): Rational bargaining and justification. J. Bus. Ethics 2006, 68, 259-281. [CrossRef]

4. Kirwan, J. Alternative strategies in the UK agro-food system: Interrogating the alterity of farmers' markets. Sociol. Rural. 2004, 44, 395-415. [CrossRef] 
5. Brunori, G.; Rossi, A.; Guidi, F. On the new social relations around and beyond food. Analysing consumers' role and action in gruppi di acquisto solidale (solidarity purchasing groups). Sociol. Rural. 2012, 52, 1-30. [CrossRef]

6. Brown, C.; Miller, S. The impacts of local markets: A review of research on farmers markets and community supported agriculture (csa). Am. J. Agric. Econ. 2008, 90, 1298-1302. [CrossRef]

7. Feldmann, C.; Hamm, U. Consumers' perceptions and preferences for local food: A review. Food Qual. Preference 2015, 40, 152-164. [CrossRef]

8. Onozaka, Y.; Mcfadden, D.T. Does local labeling complement or compete with other sustainable labels? A conjoint analysis of direct and joint values for fresh produce claim. Am. J. Agric. Econ. 2011, 93, 693-706. [CrossRef]

9. Zepeda, L.; Li, J. Who buys local food? J. Food Distrib. Res. 2006, 37, 1-11.

10. Fonte, M. Food consumption as social practice: Solidarity purchasing groups in rome, Italy. J. Rural Stud. 2013, 32, 230-239. [CrossRef]

11. Brown, H.S.; de Jong, M.; Levy, D.L. Building institutions based on information disclosure: Lessons from gri's sustainability reporting. J. Clean. Prod. 2009, 17, 571-580. [CrossRef]

12. Brunori, G.; Galli, F.; Barjolle, D.; van Broekhuizen, R.; Colombo, L.; Giampietro, M.; Kirwan, J.; Lang, T.; Mathijs, E.; Maye, D. Are local food chains more sustainable than global food chains? Considerations for assessment. Sustainability 2016, 8, 449. [CrossRef]

13. Grivins, M.; Tisenkopfs, T.; Stojanovic, Z.; Ristic, B. A comparative analysis of the social performance of global and local berry supply chains. Sustainability 2016, 8, 532. [CrossRef]

14. Schwarz, J.; Schuster, M.; Annaert, B.; Maertens, M.; Mathijs, E. Sustainability of global and local food value chains: An empirical comparison of peruvian and belgian asparagus. Sustainability 2016, 8, 344. [CrossRef]

15. Galli, F.; Bartolini, F.; Brunori, G. Handling diversity of visions and priorities in food chain sustainability assessment. Sustainability 2016, 8, 305. [CrossRef]

16. Schmitt, E.; Keech, D.; Maye, D.; Barjolle, D.; Kirwan, J. Comparing the sustainability of local and global food chains: A case study of cheese products in switzerland and the UK. Sustainability 2016, 8, 419. [CrossRef]

17. Touzard, J.-M.; Chiffoleau, Y.; Maffezzoli, C. What is local or global about wine? An attempt to objectivize a social construction. Sustainability 2016, 8, 417. [CrossRef]

18. De Laurentiis, V.; Hunt, D.V.; Rogers, C.D. Overcoming food security challenges within an energy/water/food nexus (ewfn) approach. Sustainability 2016, 8, 95. [CrossRef]

19. Oostindie, H.; van Broekhuizen, R.; de Roest, K.; Belletti, G.; Arfini, F.; Menozzi, D.; Hees, E. Sense and non-sense of local-global food chain comparison, empirical evidence from dutch and italian pork case studies. Sustainability 2016, 8, 319. [CrossRef]

20. Singh, R.K.; Murty, H.R.; Gupta, S.K.; Dikshit, A.K. An overview of sustainability assessment methodologies. Ecol. Indic. 2009, 9, 189-212. [CrossRef]

21. Wilson, J.; Tyedmers, P.; Pelot, R. Contrasting and comparing sustainable development indicator metrics. Ecol. Indic. 2007, 7, 299-314. [CrossRef]

22. Munda, G. Social Multi-Criteria Evaluation for a Sustainable Economy; Springer: Berlin, Germany, 2008.

23. Gamboa, G.; Kovacic, Z.; Di Masso, M.; Mingorría, S.; Gomiero, T.; Rivera-Ferré, M.; Giampietro, M. The complexity of food systems: Defining relevant attributes and indicators for the evaluation of food supply chains in spain. Sustainability 2016, 8, 515. [CrossRef]

24. Smith, J.; Lang, T.; Vorley, B.; Barling, D. Addressing policy challenges for more sustainable local-global food chains: Policy frameworks and possible food "futures". Sustainability 2016, 8, 299. [CrossRef]

(c) 2016 by the authors; licensee MDPI, Basel, Switzerland. This article is an open access article distributed under the terms and conditions of the Creative Commons Attribution (CC-BY) license (http://creativecommons.org/licenses/by/4.0/). 